\title{
Comparing Employee Attitudes towards Individualism-Collectivism across Public and Private Sector Organizations*
}

\author{
Taejun Cho** and Sue R. Faerman***
}

\begin{abstract}
One hundred thirty one responses from public employees and 154 responses from private employees were analyzed to compare employee attitudes towards individualism-collectivism across public and private sector organizations. The present study provides knowledge to public management by showing that some organizational characteristics of public sector organizations (i.e., goal ambiguity, red tape, and public-service motivation) make the public-private distinction, whereas others do not. Additionally, we found that the distinction has been blurred as New Public Management (NPM) has been adopted recently in the public sector. Finally, we support the two-factor model of organizational collectivism and individualism, as well as report that organizational individualism differentiates public and private sector organizations. The theoretical and practical implications of the findings are discussed.
\end{abstract}

Keywords: Public-Private Distinction, Organizational Individualism and Collectivism, Organizational Characteristics of Public Sector Organizations

* This paper was presented at the annual meeting of the SECoPA 2006 (Southeastern Conference for Public Administration) in Athens, GA in the United States. We appreciate Dr. David P. McCaffrey and Dr. Richard H. Hall, and Dr. David Pitts for their review and comments.

** Taejun Cho received Ph.D. degree from the Department of Public Administration and Policy at the University at Albany, State University of New York in May 2008. His research focuses on human resource management, empowerment, and individual performance. Email: taejunc@gmail.com.

*** Sue R. Faerman is Distinguished Teaching Professor in the Department of Public Administration and Policy and Vice Provost for Undergraduate Education at the University at Albany, State University of New York. Her research interests focus on leadership and organization development. Email: sfaerman@uamail.albany.edu.

Manuscript received June 2008; out for review July 2008; review completed August 2008; accepted August 2008.

The Korean Journal of Policy Studies, Vol. 23, No. 1, 19-47 (2008)

(C) 2008 by the GSPA, Seoul National University 


\section{INTRODUCTION}

The public-private distinction has long been debated in public administration. Following the "separate but equal" doctrine (Murray 1975, 364), the generic school of management argues that the similarity between both sectors leads to transferability of management techniques (Perry and Porter 1982) and generalizability of organization theory (Meyer 1982). Its basic assumption is that the similarities outweigh the differences. As a counterpoint, "the integrationist movement" emphasizes the differences (Frumkin and Galaskiewicz 2004; Simon 1995). As one criterion for the distinction, Rainey (1989) notes that organization activities in the two sectors are controlled differently by government authorities and economic markets, respectively (Dixit 1997). However, the literature has rarely considered organizational culture as a factor that may influence the distinction [see Bozeman (1998) for an exception]. Integrationists (e.g., Fottler 1981; Segal 1974) note that environmental factors affect the distinction, but they have not focused on organizational culture as one criterion that might differentiate the context of the two sectors.

Although there have been debates about the distinction, recent scholarly disputes have been diminished because the New Public Management (NPM), with its underlying emphases on economic-based performance and efficiency (Denhardt and Denhardt 2000; Hood and Peters 2004; Stark 2002), has been introduced in the public sector (Rainey 1997). However, a counterargument notes that public sector organizations have their own unique public values, democratic accountability, and due process (Box et al. 2001; Goodsell 1993; Riccucci 2001). That is, they have maintained that one must consider differences between the public and private sectors when considering various organizational practices. Inconsistent conclusions about this distinction suggest that further research on this topic is needed.

Based on these debates, the purpose of the present study is to examine whether the two sectors have different organizational cultures, which are related to the particular type of work done by the two sectors. Using the individualism-collectivism concept, we investigate whether public employees are more likely to report higher levels of organizational collectivism than employees in the private sector within a societal culture that is generally seen as having a collectivist character. Additionally, as factors to distinguish the two sectors, this study examines the properties of public sector organizations-i.e., goal ambiguity, red tape, and public-service motivation (Bozeman 1993; Chun and Rainey 2005; Perry and Wise 1990). Thus, we examine whether the relationships between these characteristics and organizational individualism and collectivism differ across organizational sectors. 


\section{CONCEPTUAL FRAMEWORK AND HYPOTHESIS}

\section{Individualism-Collectivism as a Dimension of Organizational Culture}

Organizational culture is defined as a set of shared cognitive and behavioral experiences within a social unit (Chatman and Jehn 1994; Cooke and Rousseau 1988; Schein 1996). In particular, Pettigrew $(1979,574)$ notes, "Culture is the system of such publicly and collectively accepted meanings operating for a given group at a given time." Thus, researchers and practitioners have widely examined this construct because every organization has its own value systems (Hofstede 1985), necessitating different management strategies according to the organizational culture (Bates et al. 1995; Schneider 1988). Additionally, there may be a mismatch between organizational and societal cultures because some organizations need to develop their own distinctive value systems, which may run counter to cultural orientations in society (Earley and Gibson 1998). As one dimension to measure societal or national culture (Hofstede 1980), studies (e.g., Hui and Triandis 1986; Kemmelmeier et al. 2003; Wagner 1995) have examined individualism-collectivism, where individualistic cultures focus on personal interests and goals (or the self), internal locus of control, self-actualization, and independence (Kagitcibasi 1987; Ramamoorthy and Carroll 1988); and collectivist cultures emphasize shared interests (or the collectivity), social norms, in-group goals, and consensus (Ramamoorthy and Flood 2004; Schwartz 1990). However, Earley and Gibson (1998) argue that the concept of individualism-collectivism has limitations because it is negatively correlated with power distance, which is one dimension of Hofstede's (1980) measurement, and thus not a separate dimension. In addition, Hofstede's (1980) work has been criticized on the basis of methodological disadvantages, such as the representativeness of the sample and the validity of dimensions (Voronov and Singer 2002).

While the concept was initially developed to compare cultural differences across societies, it has also been used to measure organizational culture (Hofstede and Spangenberg 1987; Robert and Wasti 2002). That is, some researchers have argued that the concept was derived from research at the organizational level, which examined an international corporation's culture in both western and eastern nations (Jaeger 1986). In particular, Earley and Gibson $(1998,279)$ note, "Organizational cultures can be characterized as individualistic or collectivistic." Additionally, Chatman and Barsade (1995) note that individualism-collectivism characterizes how work is conducted in a specific organization. Thus, some organizations may be described as having a culture that emphasizes individual goals, growth, and responsibilities (i.e., organizational individualism) (Triandis 1989), whereas others have culture that focuses on shared values, 
conformity with in-groups norms, and cooperative behaviors (i.e., organizational collectivism) (Cox et al. 1991).

In general, Korea has been classified as being collectivist at the societal level (Hofstede 1980; 1997). However, there have been few studies examining culture in using the construct at the organizational level in the literature. Initially, we expect that public sector organizations in Korea, which have been less exposed to competitive and globalized environments than private ones, are more likely to have collectivist cultures. Our expectation is derived from the assumption that public employees are rarely oriented to market-based norms, self-reliance, and independence, and are more committed to a public-service ethic (Mosher 1968) and non-measurable aspects of work (e.g., a sense of loyalty). That is, these traits lead to an emphasis on collectivist orientations. In opposition, private sector organizations are more likely to put emphases on individualistic orientations, although societal culture is classified as being a collectivist culture. That is, employees in the private sector are more sensitive to individual-based performance and competitive environments (e.g., pay-for-performance and a globalized external context) than are those who work in the public sector. These properties in private sector organizations are related to organizational individualism because they generally emphasize individual development and autonomy (Triandis 1995). Based on the literature, we develop hypotheses that organizational individualism and collectivism differentiate the public sector from the private sector. Thus,

Hypothesis 1a: Employees in public sector organizations will report lower levels of organizational individualism than will their counterparts in private sector organizations.

Hypothesis 1b: Employees in public sector organizations will report higher levels of organizational collectivism than will their counterparts in private sector organizations.

\section{Properties Differentiating Public and Private Sector Organizations}

The generic school of management argues that management techniques and organization theories can be applied to all organizations because the two sectors have overlapping and mixed characteristics (Fottler 1981). Murray $(1975,371)$ notes that there is "an increasing convergence in management processes in the public and private sectors" and argues that there are no applicable criteria for differentiation. Solomon $(1986,247)$ notes, "Management functions, whether in the private or the public sector, are conceptually similar." In addition, market- and business-based management tech- 
niques have been increasingly adopted in public sector organizations (Chubb and Moe 1988; Osborne and Plastrik 1997). These notes are justification to assert the similarity. However, the integration model assumes that private managers are exposed to a greater degree to economic markets, whereas public managers are influenced by particular procedures (Bozeman and Rainey 1998; Wilson 1989), external constituencies (Coursey and Bozeman 1990; Kingsley and Reed 1991), political constraints (Bozeman and Loveless 1987; Lachman 1985), and public values (Frederickson and Hart 1985). Researchers supporting the distinction have taken either the core approach that maintains the difference by legal status (Antonsen and Jorgensen 1997; Kurland and Egan 1999; Lynn 1981), or the dimensional approach that argues for the distinction by a matter of degree (Bozeman 1987).

There have been debates about the public-private distinction, but it has been recently eroded or blurred due to business-like reforms in the public sector. Haque (2001, $65)$ notes, " $\ldots$ the concern for ascertaining the status of public service as an authentic public domain seems to have diminished worldwide under the emerging market-driven mode of governance." However, economic-oriented reforms have not been always succeeded in the public sector (Haque 2001). The reforms may increase performance, but managers must consider the public sector's properties or characteristics in order to successfully introduce the advantages of reinventing government. Based on this argument, public sector organizations have organizational properties that may differ from private ones. Considering the public-private distinctions, Rainey and Bozeman (2000) note that there are specific dimensions-goals, organizational structure, and workrelated values - that make the distinction. Related to these dimensions, we identify three properties or variables (i.e., goal ambiguity, red tape, and public-service motivation) that differentiate the two sectors.

\section{Work Context}

Work context is defined as "the characteristics of the overall organizational setting, such as the organization's goals or degree of formalization, in which the employee must perform the work" (Wright and Davis 2003, 74). Wright (2001) notes that work context is one criterion to explain sector differences. Following Wright's (2001) argument, we focus on an organizational goal (i.e., goal ambiguity) that is one variable to distinguish the two sectors.

Goal Ambiguity. Ambiguity is defined as "the state of having many ways of thinking about the same circumstances or phenomenon" (Feldman 1989, 5). Chun and Rainey $(2005,2)$ define goal ambiguity as "the extent to which an organizational goal or set of goals allows leeway for interpretation." Related to the public-private distinction, however, the goal ambiguity literature has reported some mixed empirical results. 
Some reported a higher level of goal clarity in the public sector (Lan and Rainey 1992; Rainey, 1983), whereas others reported that public managers have more vague goals than do private managers (Rainey and Bozeman 2000).

Even though there have been mixed empirical results, the present study expects that public sector organizations have a greater vagueness of organizational goals than private ones, due the following reasons: Public sector organizations rarely have economic or financial indicators to measure performance because their goals are associated with values (Rainey et al. 1995). Underlying value-laden goals, they must consider the aspects of publicness, such as social equity, democratic accountability, and responsiveness (Wright \& Davis 2003). Rather than pointing out measurable indicators, they are concerned with non-measurable goals due to the importance of publicness. In addition, they have more multiple and conflicting goals (Bretschneider 1990) because they are intertwined with external entities, including political oversight and citizen involvement. Different actors' interests in goal-setting processes cause multiple and conflicting objectives and directions in practice.

Based on the literature, the present study hypothesizes that goal ambiguity is one factor in making the public-private distinction. Furthermore, we examine whether organizational sector moderates the relationships between goal ambiguity and organizational individualism and collectivism, respectively. Thus,

Hypothesis 2a: Employees in public sector organizations will report higher levels of goal ambiguity than will their counterparts in private sector organizations.

Hypothesis 2b: Organizational sector moderates the relationship between goal ambiguity and organizational individualism.

Hypothesis 2c: Organizational sector moderates the relationship between goal ambiguity and organizational collectivism.

\section{Organizational Structure}

Among the structural properties that can be used to compare the both sectors, red tape has been discussed as a key indicator (Scott and Pandey 2000). Public sector organizations inherently have more red tape than private ones (Baldwin 1990; Rosenfeld 1984), but others have insisted that there are few differences in the level of red tape across the two sectors (Buchanan 1975).

Red Tape. Bozeman $(2000,12)$ defines it as "rules, regulations, and procedures that remain in force and entail a compliance burden but do not advance the legitimate 
purposes the rules were intended to serve." Researchers have noted that it causes excessive constraints and rigidities, inefficient organizational functioning, and procedural delays in personnel and procurement (Bozeman and Scott 1996; Bretschneider 1990; Steel and Warner 1990).

Red tape would be conceptually similar to formalization that focuses on the number and extensiveness of organizational rules, but the both concepts have no systematic relation (Pandey and Kingsley 2000; Pandey and Scott 2002). In particular, red tape is defined as "a bureaucratic pathology" (Bozeman and Scott 1996, 3), while formalization is named as "the 'physiology' of the organization" (Bozeman and Scott 1996, 8). Researchers have supported this perspective because red tape does not positively meet societal and organizational objectives and goals (Bozeman 1993; Bozeman and Scott 1996). Another issue is whether red tape is beneficial to organizational functioning. Kaufman $(1977,4)$ notes, "One person's 'red tape' may be another's treasured safeguard." Thus, red tape guarantees accountability, protects public interest, and controls employees' behavior, as well as providing a rationale for rules and procedures (Goodsell 2004). Baldwin (1990) also notes that it discourages employees' arbitrary decision making. However, due to the burdensome procedures and administrative delays in personnel processes, red tape leads to negative results (Pandey and Bretschneider 1997). Supporting this argument, Rosenfeld $(1984,603)$ notes, "[R]ed tape refers to guidelines, procedures, forms, and governmental intervention that are perceived as excessive, unwieldy, or pointless in relationship to decision-making or implementation of decisions."

Based on the literature, the present study expects that public sector organizations have more red tape than private ones, for the following reasons. First, they innately have more formal rules and regulations to ensure procedural accountability and to monitor abusive administrative authority. For monitoring employees' behaviors and protecting appropriate procedures, public sector organizations would require additional rules. Second, they have more unclear or non-measurable goals and complicated interests than do private ones. They are closely intertwined with multiple/conflicting goals, a complicated web of external stakeholders, and internal/external oversight. These characteristics cause an abundance of formal and informal rules to meet legal, political, and administrative requirements, especially in personnel and procurement processes.

Considering the debates and arguments, the present study examines whether red tape makes the public-private distinction. Further, we examine whether organizational sector moderates the relationships between red tape and organizational individualism and collectivism, respectively. Thus, 
Hypothesis 3a: Employees in public sector organizations will report higher levels of red tape than will their counterparts in private sector organizations.

Hypothesis 3b: Organizational sector moderates the relationship between red tape and organizational individualism.

Hypothesis 3c: Organizational sector moderates the relationship between red tape and organizational collectivism.

\section{Individuals' Work-Related Values}

Public employees have their own work-related values, including ethical values (Smith 2003; Wittmer and Coursey 1996), motivation (Wright 2001), and reward preference (Maidani 1991). Researchers supporting the public-private distinction have found that public employees emphasize altruistic motives and prosocial behaviors (Balfour and Wechsler 1990) and public services over market-based rewards (Rawls et al. 1975; Staats 1988), whereas others have argued the similarity outweighs the distinction (Emmert \& Taher 1992).

Public-Service Motivation (PSM). PSM is defined as "an individual's predisposition to respond to motives grounded primarily or uniquely in public institutions and organizations" (Perry and Wise 1990, 368). PSM assumes that public employees' motives-i.e., "psychological deficiencies or needs that an individual feels some compulsion to eliminate" (Perry 1996, 6) — may be differentiated from private employees' ones because the economic-based motives that focus on extrinsic rewards-i.e., "rewards given to the individual by someone else" (Crewson 1997, 501)-may not apply to the public sector. Public employees place greater value on public service than on market-based profit (Crewson 1995), and more on norm-based and affective motives-e.g., public interest and social equity (Frederickson 1971) - than on rational motives, such as financial rewards (Solomon 1986) and job security (Wittmer 1991). However, some extant literature has reported that there is a lower level of public-service ethic (Gabris and Simo 1995; Jurkiewicz et al. 1998) and no differences in preference for financial rewards (Crewson 1997; Maidani 1991).

Even though there have been some mixed results, the present study expects that public employees place higher values on service ethic, for the following reasons. First, they have unique motivators that are different from private ones. The private sector concentrates on market-based outcomes, whereas the counterpart focuses on "democratic values" (Gabris \& Simo 1995, 35). Although there have been efforts to introduce market-based reforms in the public sector, it has not been easy to apply the reforms to the public sector because public employees need to serve public interests. Supporting 
this argument, Frederickson and Hart (1985) note that business-oriented values should be avoided in public administration in order to emphasize public interests. Second, public employees have no "strong situations," which are characterized by clear goals and extrinsic rewards (Shamir 1991, 407). Even though private sector organizations are under "strong situations" where one measures efficiency and performance, public employees are unfamiliar with "strong situations" because they have no clear criteria of financial preference. Brown $(1996,252)$ notes that "governance and reward systems in the different types of organization may create different needs and expectations."

Considering these statements, the present study expects that PSM makes the publicprivate distinction. Also, we test whether organizational sector moderates the relationships between PSM and organizational individualism and collectivism, respectively. Thus,

Hypothesis 4a: Employees in public sector organizations will report higher levels of public-service motivation than will counterparts in private sector organizations.

Hypothesis 4b: Organizational sector moderates the relationship between publicservice motivation and organizational individualism.

Hypothesis 4c: Organizational sector moderates the relationship between publicservice motivation and organizational collectivism.

\section{METHODOLOGY}

\section{Sample}

Data were collected from public and private employees in Korea. The public sampling frame was drawn from employees working in the largest metropolitan city government. A survey instrument was administered in seven divisions from the city government, as well as three administrative districts that are the lowest autonomous administration units in the government. Each division and administrative district was allocated 30 questionnaires. Because they provided the lists of employees on their website, the researcher could contact the head of a work unit, and ask to distribute the questionnaire to 30 employees in the unit. The private sampling frame was drawn from employees working in companies that are listed in the main tracking index, the Korean Composite Stock Price Index (KOSPI). We administered a survey instrument 
at ten organizations, especially, high-tech and information technology (IT) work units in globalized companies which are registered in KOSPI. Because most private firms do not provide the lists of employees on their website, the researcher had to rely on personal contacts in these firms. Using snowball sampling, the researcher personally contacted colleagues who work in the targeted companies, then asked them to contact the heads of each work unit in these companies. Unit heads were then asked to distribute the questionnaire to 30 employees in their work units.

Of the total 600 questionnaires, 295 surveys were returned (49.2\% response rate). The data set consisted of 134 responses from public employees (44.6\% response rate) and 161 responses from private employees (53.0\% response rate). However, responses from only 131 (public) and 154 (private) were usable for the research. The former represented divisions in city government $(55 \%)$ and administrative districts $(45 \%)$. The latter represented banks (19.6\%), globalized companies (24.8\%), securities and insurance $(29.4 \%)$, IT (23.5\%), and others $(2.6 \%)$.

\section{Variables}

Goal ambiguity may be operationalized by the lack of goal clarity, which indicates the extent to which an organization has a clear organizational mission and clear goal, or by situations where there are a number of multiple interpretations of the same state of affairs. Measuring goal ambiguity, we used Rainey et al.'s (1995) scales (e.g., "This organization's mission is clear to most everyone who works here (R)") that were developed to examine organizational missions and clear goals that lead to organization productivity and performance.

Rainey et al. (1995) developed two dimensions of red tape: (a) general administrative red tape, which consists of general red tape and rule enforcement red tape, and (b) personnel red tape, which focuses on personnel rule constraints, personnel delay, and the number of decision makers. The present study used two dimensions, including rule enforcement red tape (e.g., "The employees here are constantly being watched to check for rule violations") and personnel rule constraints (e.g., "Even if a manager is a poor performer, formal rules make it hard to remove him or her from the organization").

Public-service motivation is generally operationalized by four dimensions, including attraction to public policy making, commitment to the public interest/civic duty, compassion, and self-sacrifice (Perry 1996). We used only two dimensions-commitment to the public interest/civic duty (e.g., "I unselfishly contribute to my community") and self-sacrifice (e.g., "I think people should give back to society more than they get from it")-_from Perry's (1996) measurements because we define PSM as placing a greater value on a service ethic and intrinsic rewards. 
The Organizational Culture Scale, which was developed by Robert and Wasti (2002), was used to measure an individual's perception regarding individualism and collectivism at the level of organization. We used their six items to measure organizational individualism (e.g., "Competition between employees is accepted") and their seven items to measure organizational collectivism (e.g., "Everyone is kept informed about major decisions that affect the success of the company"). Responses for all items were measured by a 5-point scale (1, "strongly disagree," to 5 "strongly agree").

\section{Data Collection Procedure and Analysis}

Because the first language of the participants in this study is Korean, we needed to translate the questionnaire, which had been developed in English, into Korean. A Korean researcher who holds a $\mathrm{Ph} . \mathrm{D}$. degree in public administration reviewed the translation and made several modifications to clarify specific items. A request letter, which contained the research purpose and method, as well as confidentiality clauses, was mailed to each director. Each director was asked to distribute to employees a consent letter, which explained the research purposes and confidentiality, along with the survey questionnaires. We provided a stamped envelope to enhance the response rate.

Testing whether public employees have more collectivist orientations than do private employees, we conducted a univariate analysis of variance. This method was also employed to examine whether there were differences between public and private sector employees in their report of the properties associated with the public sector. Next, hierarchical regression analyses were performed to investigate whether organizational sector moderates the relationship between the properties and organizational individualism and collectivism, respectively.

\section{RESULTS}

\section{Descriptive Statistics}

The descriptive statistics for all variables are shown in Table 1. We noted that PSM would be measured by two dimensions (e.g., commitment to the public interest/civic duty and self- sacrifice), but the first dimension was excluded from further analyses because the reliability was extremely low (Cronbach's alpha $=.29) .{ }^{1}$ Additionally, the reliabilities

1. Initially, Perry (1996) developed five items for measuring commitment to the public interest/ civic duty as one dimension of PSM. However, the present study excluded two items ("I con- 
for Personnel Rule Red Tape (.64) and Organizational Individualism (.67) were minimally acceptable. The reliabilities for other scales were satisfactory (i.e., above .75).

Table 1. Reliabilities, Correlations, Means, and Std. Deviation

\begin{tabular}{l|c|c|c|c|c|c|c|c}
\hline & Mean & S.D. & 1 & 2 & 3 & 4 & 5 & 6 \\
\hline 1. Goal ambiguity & 2.45 & .74 & $(.74)$ & & & & & \\
2. Public-service motivation & 2.95 & .56 & -.08 & $(.76)$ & & & & \\
3. Rule enforcement red tape & 3.01 & .89 & -.10 & .05 & $(.78)$ & & & \\
4. Personnel rule red tape & 3.33 & .67 & .06 & .05 & $.29 * *$ & $(.64)$ & & \\
5. Organizational collectivism & 2.92 & .66 & $-.36 * *$ & $.21 * *$ & .01 & $-.14 * *$ & $(.81)$ & \\
6. Organizational individualism & 3.16 & .55 & $-.28 * *$ & .02 & -.01 & $-.29 * *$ & $.34 * *$ & $(.67)$ \\
\hline
\end{tabular}

* Correlation is significant at the .05 level (2-tailed).

** Correlation is significant at the .01 level (2-tailed).

Note: Cronbach's alpha is presented in parentheses.

\section{Tests of Hypotheses}

The first set of hypotheses predicted that organizational individualism and collectivism would make the public-private distinction. To test Hypotheses 1a and 1b, we conducted a univariate analysis of variance based on the complete data set of 285 respondents. While we initially expected that they would differentiate public and private sector organizations, the results partially supported the hypotheses: organizational individualism statistically differentiated public and private sector organizations, but organizational collectivism did not (see Table 2).

Table 2. Univariate Analysis of Variance

\begin{tabular}{l|c|c|r|l}
\hline & Public & Private & \multicolumn{1}{|c|}{$F$} & \multicolumn{1}{c}{ Sig. } \\
\hline Goal Ambiguity & $2.52(.67)$ & $2.40(.78)$ & 2.22 & .137 \\
Public-service Motivation & $3.05(.55)$ & $2.86(.56)$ & 8.81 & $.003^{* *}$ \\
Rule Enforcement Red Tape & $3.23(.79)$ & $2.91(.94)$ & 9.41 & $.002^{* *}$ \\
Personnel Rule Red Tape & $3.65(.54)$ & $3.07(.65)$ & 64.47 & $.000^{* * *}$ \\
Organizational Collectivism & $2.93(.60)$ & $2.91(.71)$ & .13 & .722 \\
Organizational Individualism & $2.96(.48)$ & $3.34(.56)$ & 38.30 & $.000^{* * *}$ \\
\hline $\mathrm{N}$ & 131 & 154 & & \\
\hline
\end{tabular}

Note:** $p<.01 ; * * * p<.001$.

Values in parentheses are standard deviation.

sider public service my civic duty" and "Meaningful public service is very important to me") because these items would not be appropriate in measuring private employees' attitudes. The exclusion of these items may have led to an extraordinarily low level of reliability. 
Hierarchical ordinary least squares regression analyses were used to test Hypothesis 2 through 4 . Table 3 and Table 4 present the results of the analyses with organizational individualism and collectivism as the dependent variable, respectively. Model 1 , which only included characteristics that have been seen as the properties of public sector organizations, explained almost 16 percent of the variance in organizational individualism (Table 3) and nearly 18 percent of the variance in organizational collectivism (Table 4). In Model 2 in Table 3 and Table 4, we introduced organizational sector as a dummy variable ("pubprivate," public $=1$ and private $=0$ ). The introduction of the dummy variable explained an additional 0.7 percent of the variance in organizational collectivism, whereas it explained an additional 5.5 percent $(p<.001)$ of the variance in organizational collectivism in Model 2 of Table 3.

Table 3. Hierarchical Regression Analyses Predicting Organizational Individualism

\begin{tabular}{|c|c|c|c|c|c|c|}
\hline & Model 1 & Model 2 & Model 3 & Model 4 & Model 5 & Model 6 \\
\hline $\begin{array}{l}\text { Public-service } \\
\text { Motivation }\end{array}$ & .008 & .049 & .090 & .090 & .090 & .092 \\
\hline $\begin{array}{l}\text { Rule Enforcement } \\
\text { Red Tape }\end{array}$ & .057 & .073 & .077 & .079 & .093 & $.120^{+}$ \\
\hline $\begin{array}{l}\text { Personnel Rule } \\
\text { Red Tape }\end{array}$ & $-.293 * * *$ & $-.187 * *$ & $-.189 * *$ & $-.195 * *$ & $-.197 * *$ & $-.286 * * *$ \\
\hline Goal Ambiguity & $-.257 * * *$ & $-.235 * * *$ & $-.240 * * *$ & $-.208 * *$ & $-.206 * *$ & $-.193^{* *}$ \\
\hline pubprivate & & $-.266 * * *$ & -.026 & .158 & .226 & -.333 \\
\hline $\begin{array}{l}\text { Public-service } \\
\text { Motivation x } \\
\text { pubprivate }\end{array}$ & & & -.253 & & & \\
\hline $\begin{array}{l}\text { Goal Ambiguity x } \\
\text { pubprivate }\end{array}$ & & & & -.158 & & \\
\hline $\begin{array}{l}\text { Rule Enforcement } \\
\text { Red Tape } x \\
\text { pubprivate }\end{array}$ & & & & & -.070 & \\
\hline $\begin{array}{l}\text { Personnel Rule } \\
\text { Red Tape } x \\
\text { pubprivate }\end{array}$ & & & & & & $.642^{+}$ \\
\hline$R^{2}$ & .158 & .213 & .215 & .217 & .217 & .226 \\
\hline$\Delta R^{2}$ & & $.055^{* * *}$ & .002 & .002 & .000 & $.009^{+}$ \\
\hline$F$ & $13.1^{* * *}$ & $15.1^{* * *}$ & $12.7 * * *$ & $11.0 * * *$ & $9.6^{* * *}$ & $8.9 * * *$ \\
\hline
\end{tabular}

a. Dependent variable: Organizational individualism

Note: $+p<.1 ;{ }^{*} p<.05 ;{ }^{* *} p<.01 ;{ }^{* * *} p<.001$.

Regression weights are standardized coefficients. 
The second set of hypotheses focused on goal ambiguity. Hypotheses 2a predicted that public employees would report higher levels of goal ambiguity than would their counterparts in the private sector. To examine whether there are differences in goal ambiguity across the sectors, we conducted a univariate analysis of variance. The results did not show statistically significant differences in goal ambiguity across the sectors (see Table 2). Thus, the result did not support Hypothesis 2a. Hypotheses 2b and $2 c$ examined whether organizational sector moderates the relationship between goal ambiguity and organizational individualism (Model 4 in Table 3) and collectivism (Model 4 in Table 4), respectively. The interaction terms in both regression models were nonsignificant, suggesting that organizational sector would not have a moderating role in this study. Thus, Hypotheses $2 \mathrm{~b}$ and $2 \mathrm{c}$ were not supported.

Table 4. Hierarchical Regression Analyses Predicting Organizational Collectivism

\begin{tabular}{l|c|c|c|c|c|c}
\hline & Model 1 & Model 2 & Model 3 & Model 4 & Model 5 & Model 6 \\
\hline $\begin{array}{l}\text { Public-service } \\
\text { Motivation }\end{array}$ & $.185^{* *}$ & $.171^{* *}$ & $.263^{* * *}$ & $.263^{* * *}$ & $.264^{* * *}$ & $.264^{* * *}$ \\
\hline $\begin{array}{l}\text { Rule Enforcement } \\
\text { Red Tape }\end{array}$ & .004 & -.002 & .005 & .005 & .024 & .028 \\
\hline $\begin{array}{l}\text { Personnel Rule } \\
\text { Red Tape }\end{array}$ & $-.127^{* *}$ & $-.164^{* *}$ & $-.169^{* *}$ & $-.169^{* *}$ & $-.172^{* *}$ & $-.185^{* *}$ \\
\hline $\begin{array}{l}\text { Goal Ambiguity } \\
\text { pubprivate }\end{array}$ & $-.338^{* * *}$ & $-.346^{* * *}$ & $-.357^{* * *}$ & $-.356^{* * *}$ & $-.353^{* * *}$ & $-.351^{* * *}$ \\
\hline $\begin{array}{l}\text { Public-service } \\
\text { Motivation x } \\
\text { pubprivate }\end{array}$ & & .093 & $.639^{* *}$ & $.647^{+}$ & $.734^{+}$ & .650 \\
\hline $\begin{array}{l}\text { Goal Ambiguity x } \\
\text { pubprivate }\end{array}$ & & & $-.576^{+}$ & & & \\
\hline $\begin{array}{l}\text { Rule Enforcement } \\
\text { Red Tape x } \\
\text { pubprivate }\end{array}$ & & & & & & \\
\hline $\begin{array}{l}\text { Personnel Rule } \\
\text { Red Tape x } \\
\text { pubprivate }\end{array}$ & & & .007 & & & \\
\hline$R^{2}$ & .178 & .184 & .194 & .194 & .195 & .195 \\
\hline$\Delta R^{2}$ & .007 & $.010^{+}$ & .000 & .000 & .000 \\
\hline$F$ & $12.6^{* * *}$ & $11.2^{* * *}$ & $9.6^{* * *}$ & $8.4^{* * *}$ & $7.4^{* * *}$ \\
\hline
\end{tabular}

a. Dependent variable: Organizational individualism

Note: $+p<.1 ; * p<.05 ; * * p<.01 ;{ }^{* * *} p<.001$.

Regression weights are standardized coefficients. 
The third set of hypotheses focused on red tape. Hypothesis 3 a predicted that public employees would report higher levels of red tape than would their counterparts in the private sector. Testing whether there were significant differences in red tape across the sectors, we conducted a univariate analysis of variance. The results showed statistically significant differences in red tape across the sectors (see Table 2). Thus, the present study supported Hypothesis 3a. Hypotheses $3 \mathrm{~b}$ and $3 \mathrm{c}$ tested whether organizational sector moderates the relationship between red tape and organizational individualism (Model 5 and 6 in Table 3) and organizational collectivism (Model 5 and 6 in Table 4), respectively. The interaction term in Model 6 (Table 3) was significant ( $p<$ .10 ), suggesting that organizational sector moderated the relationship between the personnel rule constraint dimension of red tape and organizational individualism. We also found that the interaction terms of the personnel rule constraint dimension of red tape and organizational sector statistically explained an additional 0.9 percent of the variance in organizational individualism (Model 6 in Table 3). However, organizational sector did not statistically moderate the relationship between the rule enforcement dimension of red tape and organizational individualism (Model 5 in Table 3). Thus, Hypothesis $3 \mathrm{~b}$ was partially supported. Conversely, organizational sector did not statistically moderate the relationships between red tape and organizational collectivism (Models 5 and 6 in Table 4). Thus, Hypothesis 3c was not supported.

The final set of hypotheses focused on Public Service Motivation (PSM). Hypothesis 4a predicted that public employees would report higher levels of PSM than private employees. Testing differences in PSM across the sectors, we performed a univariate analysis of variance. The results showed that PSM was significantly higher in public sector organizations than private ones (see Table 2). Thus, the result supported Hypothesis 4a. Organizational sector did not statistically moderate the relationship between PSM and organizational individualism (Model 3 in Table 3). Thus, Hypothesis $4 \mathrm{~b}$ was rejected. However, for organizational collectivism, the interaction term in Model 3 (Table 4) was significant $(p<.10)$, indicating that organizational sector moderated the relationship between PSM and organizational collectivism. We also found that the interaction term involving PSM and organizational collectivism explained an additional 1 percent of the variance in organizational collectivism $(p<.10)$. Thus, Hypothesis 4c was supported. 


\section{DISCUSSION AND CONCLUSION}

\section{Theoretical Implications}

The results supported that organizational individualism differentiates public sector organizations from private ones. In addition, some properties of public sector organizations (i.e., red tape and PSM) made the public-private distinction. Finally, organizational sector partially moderated the relationship between red tap and organizational individualism, and the findings supported the moderating effect of sector on the relationship between PSM and organizational collectivism.

Based on the findings, we discuss issues of organizational individualism and collectivism. First, the results showed a positive correlation between the both dimensions. As Robert and Wasti (2002) reported a positive correlation (.70) between them, we also reported a positive one (.38). However, ours was somewhat less than Robert and Wasti's (2002) research that focused on private sector organizations. A possible explanation for the lower correlation is that we collected data from both the sectors, and the sector difference may affect the result. Supporting the explanation, we also found that the correlation coefficient between organizational individualism and organizational collectivism is different in public $(r=.44)$ and private $(r=.32)$ (see Appendix A).

Second, the paired t-test reported that respondents in the two sectors presented a higher level of organizational individualism than collectivism (see Appendix B). In the public sector, the mean of organizational collectivism was 2.93 , but the value of organizational individualism was 2.96 . As well, in the private sector, the former's mean was 2.91 , but the latter's value was 3.34. Prior studies classified Korea as a collectivist culture (Hofstede 1980; 1997); however, the results showed that the respondents in this study reported that their organization is more oriented to individualistic orientations than collectivist ones. Although the present study unexpectedly found that the participants reported a higher level of organizational individualism, we have to remember that the present research focused on individualism-collectivism at the organizational level. That is, although Hofstede (1980) collected data from a multi-national organization across the world to classify cultural orientations, his study mainly focused on studying national culture. Additionally, we adopted Robert and Wasti's (2002) basic assumption and measurement that the scale would be a two-factor model, while Hofstede (1980) basically assumed that individualism-collectivism was a unidimensional continuum. Related to this issue, Robert and Wasti's (2002) measurements are totally different from Hofstede's (1980) ones. Finally, it is necessary to remember that 25 years have been passed since Hofstede (1980) conducted his research for measuring societal cultures. In Korea, younger generations are more likely to adopt an 
individualistic orientation than older generations because Korea has had much greater exposure to westernized cultures in the past two decades. In sum, although there needs to be careful consideration in interpreting the results, the present study found that we do not need to understand organizational individualism and collectivism as opposite ends of a continuum, as in Robert and Wasti's (2002) two-factor model; employees may simultaneously feel that their organizations have both individualistic orientations and collectivist ones.

A major focus of the present study was to examine the moderating role of organizational sector. In contrast to the present study's expectation, we found that organizational sector had a rather weak moderating effect on the relationship between the properties of public sector organizations and organizational individualism and collectivism, respectively. In predicting organizational individualism, only one interaction-i.e., personnel rule constraints and organizational sector-attained statistical significance $(p<.10)$, explaining only an additional 0.9 percent of variance in organizational individualism $(p<.10)$. In addition, in predicting organizational collectivism, only one interaction-i.e., between PSM and organizational sector-attained statistical significance $(p<.10)$, explaining only an additional 1.0 percent variance in organizational collectivism $(p<.10)$. However, organizational sector did not moderate the relationships between goal ambiguity and either organizational individualism or organizational collectivism. In addition, sector did not have a moderating effect on the relationship between PSM and organizational individualism, or on the relationship between red tape and organizational collectivism. One possible explanation for the limited role of organizational sector is that most public sector organizations have adopted the principles of New Public Management (NPM) as the basic philosophy (Frederickson 1991). As NPM has been introduced and developed in the public sector, the management practices and approaches in public management are more likely to focus on increasing measurable criteria (i.e., organizational performance and productivity) than on nonmeasurable ones (i.e., public values, democratic accountability, and due process). As a result, they have increasingly focused on market-based criteria and adopt businessbased reforms. Thus, the recent trends in the public administration may diminish the importance of sector difference.

Related to the issue of organizational sector, we found that public and private employees reported similar levels of what are generally considered to be the properties of public sector organizations. The present study initially expected that public employees would report higher levels of the properties than would their counterparts in the private sector. Thus, we began with the assumption of the integrationist movement, which argues that there is a clear distinction between the two sectors, rather than the generic school of management, which maintains that similarities exist between both 
sectors. To be sure, the two primary perspectives have contributed to developing organizational studies, but the present study followed the integrationist movement's viewpoint in assuming that sector difference is a major factor in understanding organizational activities; that is, the intrinsic organizational characteristics of each sector outweigh the similarities. However, we did not find major differences between the both organizations. Although the present study found the mean difference between public and private sector organizations on two variables-i.e., PSM and red tape-was significant, the overall relationship was weak. In particular, goal ambiguity showed no statistical difference between them; even though public employees reported higher levels of goal ambiguity than their counterparts in the private sector, the mean difference between them was not statistically significant $(F=2.22, p<.137)$ (see Table 2$)$. Smaller mean differences between the two sectors may lead to the limited role of organizational sector in this study.

\section{Implications for Practice}

Our results provide some implications for practicing managers in both public and private sector organizations. The present study found that organizational individualism and collectivism are positively related to each other in both sectors. Based on the findings, one can expect that employees would in general feel the coexistence of individualism and collectivism within their organization. It suggests that managers must consider the characteristics of organizational individualism and collectivism in their organization at the same time. Although the societal culture has been classified as being a collectivist culture in Korea, the respondents in both sectors reported that their organizational culture is mixed with individualistic and collectivist orientations in this study. Rather than focusing on specific cultural orientation, managers need to consider that their organization may have both individualistic and collectivist orientations; it may help leaders to understand organization members' particular attitudes and behaviors.

Second, in terms of the relationships between the properties and organizational individualism and collectivism, we found that goal ambiguity and red tape had a statistically negative impact on the both cultural orientations in both sectors. Although we do not actually know whether or not organizational individualism is a desirable culture in a specific organization, managers must try to reduce the level of these variables because organizational individualism is necessary to facilitate individual development/achievement and personal goals/responsibilities. Additionally, we found that PSM differentiates public sector organizations from private ones, but the mean difference between the two sectors was lower than we initially expected. Thus, we argue that private employees also emphasize their contributions to the public interest and 
self-sacrifice, suggesting that extrinsic rewards are not the only answer to motivate private employees. Thus, private managers should give greater consideration to intrinsic rewards as a way to motivate their employees.

\section{Limitations}

The present study has potential limitations. First, because the data are cross-sectional, we cannot assume the causality. Data were analyzed and discussed as if the properties affect organizational individualism and collectivism, but it is possible to expect converse direction. For example, organizational collectivism may be one predictor to positively influence the degree of PSM because both variables are statistically correlated. Thus, we cannot argue the causality as a correct direction because we have only cross-sectional data. Second, it is important to identify the issue of generalizability because we used different types of organizations in each sector. In particular, the private sampling frame was made up of only employees who work in IT and high-tech areas from globalized companies in Korea. As pointed out, these employees and companies should be individualistic (i.e., exhibiting organizational individualism) because internal/external environments emphasize competitiveness and individual accomplishment, although societal culture is classified as being collectivist. In addition, we did not assume the generalizability because we did not randomly distribute questionnaires to the participants. Third, there may be a possibility of social desirability and common method bias because we collected data through a self-reported questionnaire. Adopting this method, there may be biased responses. For example, there is a tendency that public employees subjectively report higher levels of PSM because they consider it as an important factor in the public sector. Additionally, we modified some measurement scales-e.g., excluding two dimensions of PSM-for the research purpose. These exclusions may have caused problems of statistical conclusion validity.

\section{Future Research}

Based on these limitations, we set out suggestions for future research. First and foremost, future studies need to use longitudinal data to clarify the causal direction between the properties and organizational individualism and collectivism, respectively. Due to the limitations of cross-sectional data, there may be a problem in arguing that the properties cause organizational individualism and collectivism. Longitudinal data can help to clarify the causal relationship between the variables. Second, researchers may wish to expand their sampling frame to other industries in the private sector in order to test whether private employees continue to report higher levels of organizational 
individualism than their counterparts in public sector organizations. In particular, researchers should expand their private sampling frame to other industries beyond IT and other high-tech areas in globalized companies to compare with their counterparts in the public sector. Finally, future research needs to use multi-source data to reduce common method variance and social desirability. Rather than relying on self-reported responses, future studies are needed to collect data from multiple sources (i.e., objective information).

Based on the findings in the present study, we have suggestions for future studies. First, researchers should collect demographic information (i.e., age and tenure) to test whether younger generations in Korea have greater tendencies toward individualistic orientations than collectivist ones. We pointed to younger generations' cultural orientations as one possible explanation for the findings that public and private employees reported higher levels of organizational individualism than collectivism. Second, researchers should further examine the public-private distinction. Although we reported that sector had a rather weak effect on the relationships in the present study, there have been some mixed reports about sector differences; some researchers have reported that sector difference has been blurred because most public sector organizations have to emphasize market-based criteria under the worldwide trends of NPM, whereas other studies have supported the distinction. Because the topic of sector difference has generated a major debate in public administration, future studies are needed to examine the roles of sector difference across the both sectors.

\section{Conclusion}

The present study has contributed to the debate concerning the public-private distinction, as well as to the literature on the relationship between the properties associated with the public sector and organizational individualism and collectivism. Despite potential limitations, we have provided useful knowledge and contributions to public management by showing that some properties of public sector organizations make the public-private distinction, whereas others do not. In addition, the present study provides additional support for the argument that the distinction between the both sectors has been blurred as NPM principles and practices have been adopted in the public sector. Finally, the present study supports the belief that organizational collectivism and individualism are positively rather than negatively correlated. In addition, this study found that organizational individualism statistically differentiates the two sectors. 


\section{Appendix A. Correlations (Public vs. Private)}

1. Public Sector Organizations $(\mathrm{N}=131)$

\begin{tabular}{l|c|c|c|c|c|c|c|c}
\hline & Mean & S.D. & 1 & 2 & 3 & 4 & 5 & 6 \\
\hline 1. Goal ambiguity & 2.52 & .67 & & & & & & \\
\hline $\begin{array}{c}\text { 2. Public-service } \\
\text { motivation }\end{array}$ & 3.05 & .55 & $-.25^{* *}$ & & & & & \\
\hline $\begin{array}{c}\text { 3. Rule enforcement } \\
\text { red tape }\end{array}$ & 3.23 & .79 & -.10 & .12 & & & & \\
\hline $\begin{array}{c}4 . \text { Personnel rule } \\
\text { red tape }\end{array}$ & 3.65 & .54 & -.12 & -.07 & .14 & & & \\
\hline $\begin{array}{c}\text { 5. Organizational } \\
\text { collectivism }\end{array}$ & 2.93 & .60 & $-.36^{* *}$ & $.16^{* *}$ & .00 & -.10 & & \\
\hline $\begin{array}{c}\text { 6. Organizational } \\
\text { individualism }\end{array}$ & 2.96 & .48 & $-.29 * *$ & .08 & .06 & -.01 & $.44 * *$ & \\
\hline
\end{tabular}

** Correlation is significant at the .01 level (2-tailed).

\section{Private Sector Organizations $(\mathrm{N}=154)$}

\begin{tabular}{l|c|c|c|c|c|c|c|c}
\hline & Mean & S.D. & 1 & 2 & 3 & 4 & 5 & 6 \\
\hline 1. Goal ambiguity & 2.40 & .78 & & & & & & \\
\hline $\begin{array}{l}\text { 2. Public-service } \\
\text { motivation }\end{array}$ & 2.86 & .56 & .019 & & & & & \\
\hline $\begin{array}{c}\text { 3. Rule enforcement } \\
\text { red tape }\end{array}$ & 2.91 & .94 & -.13 & -.04 & & & & \\
\hline $\begin{array}{c}4 . \text { Personnel rule } \\
\text { red tape }\end{array}$ & 3.07 & .65 & .12 & .00 & $.30^{* *}$ & & & \\
\hline $\begin{array}{c}\text { 5. Organizational } \\
\text { collectivism }\end{array}$ & 2.91 & .71 & $-.37^{*}$ & $.24^{* *}$ & .01 & $-.20^{*}$ & & \\
\hline $\begin{array}{c}\text { 6. Organizational } \\
\text { individualism }\end{array}$ & 3.34 & .56 & $-.25^{* *}$ & .08 & .06 & $-.26^{* *}$ & $.32^{* *}$ & \\
\hline
\end{tabular}

* Correlation is significant at the .05 level (2-tailed).

** Correlation is significant at the .01 level (2-tailed). 


\section{Appendix B. Paired T-test}

\section{Public Sector Organizations}

1. Paired Samples Statistics

\begin{tabular}{c|l|c|c|c|c}
\hline \multicolumn{2}{|c|}{} & Mean & $\mathrm{N}$ & Std. Deviation & Std. Error Mean \\
\hline \multirow{2}{*}{ Pair 1 } & Organizational Collectivism & 2.9338 & 131 & .59689 & .05215 \\
\cline { 2 - 6 } & Organizational Individualism & 2.9573 & 131 & .47718 & .04169 \\
\hline
\end{tabular}

2. Paired Samples Correlations

\begin{tabular}{|c|c|c|c|c|}
\hline & & $\mathrm{N}$ & Correlation & Sig. \\
\hline Pair 1 & Organizational Collectivism \& Organizational Individualism & 131 & .44 & .000 \\
\hline
\end{tabular}

3. Paired Samples Test

\begin{tabular}{l|l|c|c|c|c|c}
\hline \multicolumn{2}{|c|}{} & \multicolumn{3}{c|}{ Paired Differences } & \multirow{2}{*}{ df } & \multirow{2}{*}{ Sig. } \\
\cline { 3 - 5 } \multicolumn{2}{c|}{} & Mean & Std. D. & Std. E. Mean & & \\
\hline Pair 1 & $\begin{array}{l}\text { Organizational Collectivism- } \\
\text { Organizational Individualism }\end{array}$ & -.02 & .58 & .05 & 130 & .643 \\
\hline
\end{tabular}

\section{Private Sector Organizatons}

1. Paired Samples Statistics

\begin{tabular}{c|l|c|c|c|c}
\hline \multicolumn{2}{c|}{} & Mean & $\mathrm{N}$ & Std. Deviation & Std. Error Mean \\
\hline \multirow{2}{*}{ Pair 1 } & Organizational Collectivism & 2.9058 & 154 & .71297 & .05745 \\
\cline { 2 - 6 } & Organizational Individualism & 3.3403 & 154 & .55502 & .04472 \\
\hline
\end{tabular}

2. Paired Samples Correlations

\begin{tabular}{l|l|c|c|c}
\hline \multicolumn{2}{|l|}{} & $\mathrm{N}$ & Correlation & Sig. \\
\hline Pair 1 & Organizational Collectivism \& Organizational Individualism & 154 & .32 & .000 \\
\hline
\end{tabular}

3. Paired Samples Test

\begin{tabular}{|c|c|c|c|c|c|c|}
\hline & \multicolumn{3}{|c|}{ Paired Differences } & \multirow{2}{*}{$d f$} & \multirow{2}{*}{ Sig. } \\
\hline & & Mean & Std. D. & Std. E. Mean & & \\
\hline Pair 1 & $\begin{array}{l}\text { Organizational Collectivism- } \\
\text { Organizational Individualism }\end{array}$ & -.43 & .75 & .06 & 153 & .000 \\
\hline
\end{tabular}




\section{REFERENCES}

Antonsen, M., \& T. B. Jorgensen. (1997). The 'publicness' of public organizations. Public Administration, 75: 337-357.

Baldwin, J. N. (1990). Perceptions of public versus private sector personnel and informal red tape: Their impact on motivation. American Review of Public Administration, 20(1): 7-28.

Balfour, D. L., \& B. Wechsler. (1990). Organizational commitment: A reconceptualization and empirical test of public and private differences. Review of Public Personnel Administration, 10(3): 23-40.

Bates, K. A., S. D. Amundson, R. G. Schroeder, \& W. T. Morris. (1995). The crucial interrelationship between manufacturing strategy and organizational culture. Management Science, 41(10): 1565-1580.

Box, R. C., G. S. Marshall, B. J. Reed, \& C. M. Reed. (2001). New public management and substantive democracy. Public Administration Review, 61(5): 608-619.

Bozeman, B. (1987). All organizations are public: Comparing public and private organizations. San Francisco: Jossey-Bass.

Bozeman, B. (1993). A theory of government "red tape." Journal of Public Administration Research and Theory, 3(3): 273-303.

Bozeman, B. (1998). Risk culture in public and private organizations. Public Administration Review, 58(2): 109-118.

Bozeman, B. (2000). Bureaucracy and red tape. Upper Saddle River, NJ: Prentice Hall.

Bozeman, B., \& S. J. Loveless. (1987). Sector context and performance: A comparison of industrial and government research units. Administration \& Society, 19(2): 197-235.

Bozeman, B., \& H. G. Rainey. (1998). Organizational rules and the "bureaucratic personality." American Journal of Political Science, 42(1): 163-189.

Bozeman, B., \& P. Scott. (1996). Untangling conceptual knots. American Review of Public Administration, 26(1): 1-17.

Bretschneider, S. I. (1990). Management information systems in public and private organizations: An empirical test. Public Administration Review, 50(5): 536-545.

Brown, S. P. (1996). A meta-analysis and review organizational research on job involvement. Psychological Bulletin, 120(2): 235-255.

Buchanan, B. (1975). Red-tape and the service ethic: Some unexpected differences between public and private managers. Administration \& Society, 6(4): 423-444.

Chatman, J. A., \& S. G. Barsade. (1995). Personality, organizational culture, and cooperation: Evidence from a business simulation. Administrative Science 
Quarterly, 40(3): 423-443.

Chatman, J. A., \& K. A. Jehn. (1994). Assessing the relationship between industry characteristics and organizational culture: How different can you be? Academy of Management Journal, 37(3): 522-553.

Chubb, J. E., \& T. M. Moe. (1988). Politics, markets, and the organization of schools. American Political Science Review, 82(4): 1065-1087.

Chun, Y. H., \& H. G. Rainey. (2005). Goal ambiguity in U.S. federal agencies. Journal of Public Administration Research and Theory, 15(1): 1-30.

Cooke, R. A., \& D. M. Rousseau. (1988). Behavioral norms and expectations: A quantitative approach to the assessment of organizational culture. Group \& Organization Studies, 13(3): 245-273.

Coursey, D., \& B. Bozeman. (1990). Decision making in public and private organizations: A test of alternative concepts of "publicness." Public Administration Review, 50(5): 525-535.

Cox, T. H., S. A. Lobel, \& P. L. McLeod. (1991). Effects of ethnic group cultural differences on cooperative and competitive behavior on a group task. Academy of Management Review, 34(4): 827-847.

Crewson, P. D. (1995). A comparative analysis of public and private sector entrant quality. American Journal of Political Science, 39(3): 628-639.

Crewson, P. D. (1997). Public-service motivation: Building empirical evidence in incidence and effect. Journal of Public Administration Research and Theory, 7(4): 499-518.

Denhardt, R. B., \& J. V. Denhardt. (2000). The new public service: Serving rather than steering. Public Administration Review, 60(6): 549-559.

Dixit, A. (1997). Power of incentives in private versus public organizations. American Economic Review, 87(2): 378-382.

Earley, P. C., \& C. B. Gibson. (1998). Taking stock in our progress on individualismcollectivism: 100 years of solidarity and community. Journal of Management, 24(3): 265-304.

Emmert, M. A., \& W. A. Taher. (1992). Public sector professionals: The effects of public sector jobs on motivation, job satisfaction and work involvement. American Review of Public Administration, 22(2): 37-48.

Feldman, M. (1989). Order without design: Information production and policy making. Stanford, CA: Stanford University Press.

Fottler, M. D. (1981). Is management really generic? Academy of Management Review, 6(1): 1-12.

Frederickson, H. G. (1971). Toward a new public administration. In F. Marini. Scranton (Ed.), Toward a new public administration: The Minnowbrook perspective. PA: 
Chandler Publishing Company.

Frederickson, H. G. (1991). Toward a theory of the public for public administration. Administration \& Society, 22(4): 395-417.

Frederickson, H. G., \& D. K. Hart. (1985). The public service and the patriotism of benevolence. Public Administration Review, 45(5): 547-553.

Frumkin, P., \& J. Galaskiewicz. (2004). Institutional isomorphism and public sector organizations. Journal of Public Administration Research and Theory, 14(3): 283-307.

Gabris, G. T., \& G. Simo. (1995). Public sector motivation as an independent variable affecting career decisions. Public Personnel Management, 24(1): 33-51.

Goodsell, C. T. (1993). Reinvent government or rediscover it? Public Administration Review, 53(1): 85-87.

Goodsell, C. T. (2004). The case for bureaucracy: A public administration polemic (4th ed.). Washington, DC: CQ Press.

Haque, M. S. (1998). Legitimation crisis: A challenge for public service in the next century. International Review of Administrative Science, 64(1): 13-26.

Haque, M. S. (2001). The diminishing publicness of public service under the current mode of governance. Public Administration Review, 61(1): 65-82.

Hofstede, G. (1980). Culture's consequences: International differences in work related values. Beverly Hills, CA: Sage Publications.

Hofstede, G. (1985). The interaction between national and organizational value systems. Journal of Management Studies, 22(4): 347-357.

Hofstede, G. (1997). Culture and organizations: Software of the mind. New York: McGraw-Hill.

Hofstede, G., \& J. Spangenberg. (1987). Measuring individualism and collectivism at occupational and organizational level. In C. Kagitcibasi. Lisse (Ed.), Growth and progress in cross-cultural psychology. The Netherlands: Sweets \& Zeitlinger.

Hood, C., \& G. Peters. (2004). The middle aging of new public management: Into the age of paradox? Journal of Public Administration Research and Theory, 14(3): 267-282.

Hui, C. H., \& H. C. Triandis. (1986). Individualism-collectivism: A study of cross-cultural researchers. Journal of Cross-Cultural Psychology, 17(2): 225-248.

Jaeger, A. M. (1986). Organizational development and national culture: Where's the fit? Academy of Management Review, 11(1): 178-190.

Jurkiewicz, C. L., T. K. Massey, \& R. G. Brown. (1998). Motivation in public and private organizations: A comparative study. Public Productivity \& Management Review, 21(3): 230-250.

Kagitcibasi, C. (1987). Individual and group loyalties: Are they compatible? In C. 
Kagitcibasi. Lisse (Ed.), Growth and progress in cross-cultural psychology. The Netherlands: Sweets \& Zeitlinger.

Kaufman, H. (1977). Red tape: Its origins, uses, and abuses. Washington, DC: The Brookings Institute.

Kemmelmeier, M., E. Burnstein, K. Krumov, P. Genkova, C. Kanagawa, M. S. Hirshberg, H. Erb, G. Wieczorkowska, \& K. A. Noels. (2003). Individualism, collectivism, and authoritarianism in seven societies. Journal of Cross-Cultural Psychology, 34(3): 304-322.

Kingsley, G. A., \& P. N. Reed. (1991). Decision process models and organizational context: Level and sector make a difference. Public Productivity \& Management Review, 14(4): 397-413.

Kurland, N. B., \& T. D. Egan. (1999). Public vs. private perceptions of formalization, outcomes, and justice. Journal of Public Administration Research and Theory, 9(3): 437-458.

Lachman, R. (1985). Public and private sector differences: CEO's perception of their role environments. Academy of Management Journal, 28(3): 671-680.

Lan, Z., \& H. G. Rainey. (1992). Goals, rules, and effectiveness in public, private, and hybrid organizations: More evidence on frequent assertions about differences. Journal of Public Administration Research and Theory, 2(1): 5-28.

Lynn, L. E. (1981). Managing the public's business. New York: Basic Books.

Maidani, E. (1991). Comparative study of Herzberg's two-factor theory of job satisfaction among public and private sectors. Public Personnel Management, 20(4): 441-448.

Meyer, M. W. (1982). "Bureaucratic" versus "profit" organization. In B. M. Staw \& L. L. Cummings (Eds.), Research in Organizational Behavior, Vol. 4. Greenwich, CT: JAI Press.

Mosher, F. C. (1968). Democracy and the public service. New York: Oxford University Press.

Murray, M. A. (1975). Comparing public and private management: An exploratory essay. Public Administration Review, 35(4): 364-371.

Osborne, D. E., \& P. Plastrik. (1997). Banishing bureaucracy: The five strategies for reinventing government. Reading, MA: Addison-Wesley.

Pandey, S. K., \& S. I. Bretschneider. (1997). The impact of red tape's administrative delay on public organizations' interest in new information technologies. Journal of Public Administration Research and Theory, 7(1): 113-130.

Pandey, S. K., \& G. A. Kingsley. (2000). Examining red tape in public and private organizations: Alternative explanations from a social psychological model. Journal of Public Administration Research and Theory, 10(4): 779-799. 
Pandey, S. K., \& P. G. Scott. (2002). Red Tape: A review and assessment of concepts and measures. Journal of Public Administration Research and Theory, 12(4): 553-580.

Perry, J. L. (1996). Measuring public service motivation: An assessment of construct reliability and validity. Journal of Public Administration Research and Theory, 6(1): 5-22.

Perry, J. L., \& L. W. Porter. (1982). Factors affecting the context for motivation in public organizations. Academy of Management Review, 7(1): 89-98.

Perry, J. L., \& L. R. Wise. (1990). The motivational bases of public service. Public Administration Review, 50(3): 367-373.

Pettigrew, A. M. (1979). On studying organizational culture. Administrative Science Quarterly, 24(4): 570-581.

Rainey, H. G. (1983). Public agencies and private firms: Incentive structure, goals, and individual roles. Administration \& Society, 15(2): 207-242.

Rainey, H. G. (1989). Public management: Recent research on the political context and managerial roles, structures, and behaviors. Journal of Management, 15(2): 229-250.

Rainey, H. G. (1997). Understanding and managing public organizations (2nd ed.). San Francisco: Jossey-Bass.

Rainey, H. G., \& B. Bozeman. (2000). Comparing public and private organizations: Empirical research and the power of the a priori. Journal of Public Administration Research and Theory, 10(2): 447-469.

Rainey, H. G., S. Pandey, \& B. Bozeman. (1995). Research note: Public and private managers' perception of red tape. Public Administration Review, 55(6): 567573.

Ramamoorthy, N. \& S. J. Carroll. (1998). Individualism/collectivism orientations and reactions toward alternative human resource management practices. Human Relations, 51(5): 571-588.

Ramamoorthy, N., \& P. C. Flood. (2004). Individualism/collectivism, perceived task interdependence and teamwork attitudes among Irish blue-collar employees: A test of the main and moderating effects. Human Relations, 57(3): 347-366.

Rawls, J. R., R. A. Ullrich, \& O. T. Nelson. (1975). A comparison of managers entering or reentering the profit and nonprofit sectors. Academy of Management Journal, 18(3): 616-622.

Riccucci, N. M. (2001). The "old" public management versus the "new" public management: Where does public administration fit in? Public Administration Review, 61(2): 172-175.

Robert, C., \& S. A. Wasti. (2002). Organizational individualism and collectivism: 
Theoretical development and an empirical test of a measure. Journal of Management, 28(4): 544-566.

Rosenfeld, R. A. (1984). An expansion and application of Kaufman's model of red tape: The case of community development block grants. The Western Political Quarterly, 37(4): 603-620.

Schein, E. H. (1996). Culture: The missing concept in organization studies. Administrative Science Quarterly, 41(2): 229-240.

Schneider, S. C. (1988). National vs. corporate culture: Implications for human resource management. Human Resource Management, 27(2): 231-246.

Schwartz, S. H. (1990). Individualism-collectivism: Critique and proposed refinements. Journal of Cross-Cultural Psychology, 21(2): 139-157.

Scott, P. G., \& S. K. Pandey. (2000). The influence of red tape on bureaucratic behavior: An experimental simulation. Journal of Policy Analysis and Management, 19(4): 615-633.

Segal, M. (1974). Organization and environment: A typology of adaptability and structure. Public Administration Review, 34(3): 212-220.

Shamir, B. (1991). Meaning, self and motivation in organizations. Organization Studies, 12(3): 405-424.

Simon, H. A. (1995). Organizations and markets. Journal of Public Administration Research and Theory, 5(3): 273-294.

Smith, R. W. (2003). Corporate ethics officers and government ethics administrators: Comparing apples with oranges or a lesson to be learned? Administration \& Society, 34(6): 632-652.

Solomon, E. E. (1986). Private and public sector managers: An empirical investigation of job characteristics and organizational climate. Journal of Applied Psychology, 71(2): 247-259.

Staats, E. B. (1988). Public service and the public interest. Public Administration Review, 48(3): 601-605.

Stark, A. (2002). What is the new public management? Journal of Public Administration Research and Theory, 12(1): 137-151.

Steel, B. S., \& R. L. Warner. (1990). Job satisfaction among early labor force participants: Unexpected outcomes in public and private sector comparisons. Review of Public Personnel Administration, 10(3): 4-22.

Triandis, H. C. (1989). The self and social behavior in different cultural contexts. Psychological Review, 96(3): 506-520.

Triandis, H. C. (1995). Individualism and collectivism. Boulder, CO: Westview Press.

Voronov, M., \& J. A. Singer. (2002). The myth of individualism-collectivism: A critical review. The Journal of Social Psychology, 142(4): 461-480. 
Wagner, J. A. (1995). Studies of individualism-collectivism: Effects on cooperation in groups. Academy of Management Journal, 38(1): 152-172.

Wilson, J. Q. (1989). Bureaucracy: What government agencies do and why they do it. New York: Basic Books.

Wittmer, D. (1991). Serving the people or serving for pay: Reward preferences among government, hybrid sector and business managers. Public Productivity \& Management Review, 14(4): 369-383.

Wittmer, D., \& D. Coursey. (1996). Ethical work climates: Comparing top managers in public and private organizations. Journal of Public Administration Research and Theory, 6(4): 559-572.

Wright, B. E. (2001). Public-sector work motivation: A review of the current literature and a revised conceptual model. Journal of Public Administration Research and Theory, 11(4): 559-586.

Wright, B. E., \& B. S. Davis. (2003). Job satisfaction in the public sector: The role of the work environment. American Review of Public Administration, 33(1): 70-90. 